Doi: $10.18795 / \mathrm{ma} .04319$

Hakkı YAPICI

Yrd. Doç. Dr. | Assoc. Prof. Dr. Gümüşhane Üniversitesi, Edebiyat Fakültesi, Tarih Bölümü, Gümüşhane-Türkiye Gümüşhane University, Faculty of Letters, Department of History, Gümüşhane-Turkey hyapici25@hotmail.com

\title{
TARIH BOYUNCA ERZURUM'DA MEYDANA GELEN ZELZELELER
}

\begin{abstract}
Özet
İnsanoğlu, tarih boyunca birtakım tabii afetlere maruz kalmıştır. Bunların en tehlikeli ve büyüğünü ise depremler (zelzeleler) teşkil etmiştir. Anadolu'nun hemen hemen her köşesinin deprem kuşağı üzerinde bulunması hasebiyle eski çağlardan beri değişik zaman dilimlerinde büyüklü küçüklü ölçeklerde depremlere maruz kaldığı bilinmektedir. Nitekim bu coğrafyadaki birçok şehir, deprem yüzünden yok olmaktan kurtarılamamıştı. Yapılan arkeolojik kazılar ve araştırmalar bunu teyit etmektedir. Bilindiği gibi deprem, yer kabuğu içindeki fay kırıkları üzerinde biriken enerjinin aniden boşalması sonucu meydana gelen büyük yıkım ve tahribatlara sebebiyet veren doğa hadisesidir. Doğu Anadolu Bölgesi’nin tarihî çağlar boyunca aktif deprem kuşağı içerisinde yer aldığı herkes tarafından bilinen bir gerçek olmasının yanında Erzurum yerleşkesinin de aynı kaderi paylaştığ 1 görülmektedir. Bu çalışmamızda, XIX. asırda Erzurum'da yaşanmış depremler ve neticeleri arşiv belgeleri ve ilgili kaynaklar ile gazete haberleri ışığı altında ele alınacaktır.
\end{abstract}

Anahtar Kelimeler: Anadolu, Afet, Deprem, Fay.

\section{EARTHQUAKES HAPPENED IN ERZURUM THROUGHOUT HISTORY}

\begin{abstract}
Throughout history, the human have been exposed to many natural disasters, and the most dangerous and strongest of these have been the earthquakes. It has been known that there have been earthquakes of all sizes in Anatolia at different times since almost all regions of Anatolia are located on the seismic belt. Hence, many cities in this geography could not avoid being destroyed. This has been confirmed by archaelogical excavations and investigations. As is known, earthquakes are natural events which occur as a result of sudden discharge of energy accumulated on the faults in crust. In addition to the well-known fact that Eastern Anatolia Region has been an earthquake-prone region throughout history, it has been seen that Erzurum has shared the same fate. In this study, the earthquakes happened in Erzurum in the 19th century and their results will be dealt with in the light of archival records, relevant sources, and newspaper reports.
\end{abstract}

Keywords: Anatolia, Disaster, Earthquake, Fault. 


\section{GíRIŞ}

Zelzele, Arapça bir kelime olup sözlükte "bir şeyi hareket ettirmek, şiddetle sarsmak, vurmak" anlamların ihtiva eder (Devellioğlu 1995: 1176). Muallim Naci, zelzele sözcüğünü "rrgalanma, sallanıp sarsılma genellikle hareket-i arz" olarak değerlendirmektedir (Muallim Naci 2009: 764). Şemseddin Sami ise zelzele kelimesini "yeryüzünün bilinen alametlerinden kabul edilen toprağın titremesi, hareket-i arz" olarak ele almaktadır (Ş. Sami 1317: 686). Terim olarak ise "yer içindeki fay kırıkları üzerinde biriken enerjinin aniden boşalması sonucu meydana gelen yer değiştirme hareketinin yol açtı̆̆ karmaşık, elastiki dalga hareketleri” şeklinde tanımlanır. Türkçede zelzelenin yerine daha çok "deprem" kelimesi kullanılır (Arslantaş 2013: 227). Depremin (Ahmet Lütfî Efendi 1986; Ambraseys \& Finkel 2000; Güner vd. 2002; Özgür 1952) bütün doğal afetler arasında en kısa süreli gelişen, en fazla can ve mal kaybına yol açan doğa olayı olması da bir gerçektir (Güner 2007: 299).

\section{Erzurum'da 19. Yüzyılda Vuku Bulan Zelzeleler}

$\mathrm{Bu}$ yüzyılın ilk döneminde Erzurum ve havalisinde etkili bir zelzelenin olduğuna dair kayda değer bir bilgi mevcut değildir. Ancak 27 Ekim 1843 (H. 3 Şevval 1259) Cuma günü şehri sarsan bir zelzelenin vuku bulduğunu görmekteyiz. 1842 yılından itibaren Türkiye-İran-Rusya sınırında komiser görevi üstlenmiş bulunan İngiliz asıllı Robert Curzon, 27 Ekim 1843 tarihinde Erzurum'da yaşanan deprem hakkında bir görgü tanığı olarak şu bilgileri nakleder: "İkamet ettiğim ev, ağır bir geminin firtınada sallandığı gibi büyük bir gürültüyle sarsıldı. Yatak odamın bir kenarı çöktü ve ortalığı toz bulutu sardı. Bu sarsıntı öyle bir etki oluşturdu ki doğa sanki felç olmuştu. Halk bu korkunç sarsıntı karşısında büyük bir korkuya kapıldı. Bu zelzele çevrede büyük yıkımlara yol açtı. Erzurum'un medariftiharı kabul edilen Çifte Minareli Medrese'nin iki güzel minarelerinden biri görünmez oldu. Şimdiye kadar yaşamımda böyle bir depreme rastlamadım" (Curzon 1854: 151-152). Curzon'a ait bu ifadeler, depremin şehre verdiği zararların boyutları hakkında fikir yürütmemize yardımcı olacaktır. Ancak Curzon, bu deprem esnasında Erzurum'da ne kadar ölü ve yaralı olduğuna dair bir bilgi aktarmamaktadır.

19. yüzyılın ikinci döneminde Erzurum'da vuku bulan bir diğer zelzele ise 14 Temmuz 1852 tarihinde gerçekleşmiştir. Bu zelzele hakkında dönemin önemli gazetelerinden biri olan Ceride-i Havadis'in 19 Şevval 1268 tarihli, 588 numaralı sayısında şu bilgiler yer almaktadır: "Geçen Ramazan ayı içerisinde Erzurum ve havalisinde aralıklı zelzeleler 
cereyan etmiştir." Gazete haberinden de anlaşılacağı gibi birden fazla zelzelenin aralıklı meydana geldiği ifade edilmiştir.

19. yüzyılın şüphesiz ki en korkunç depremi, 2 Haziran 1859 (1 Zilkade 1275/21 Mayıs 1275) Perşembe günü saat 03.30 ile 04.00 arasında Erzurum'da vuku buldu (Ahmet Lütfî Efendi 1986: 153; Ahmet Cevdet Paşa 1986: 68; Küçük 1975: 436; Cuinet 1892: 189190; Konukçu1992: 277). Ardından 15 dakika sonra gelen ikinci deprem dalgası âdeta şehir merkezini yerle bir etti. Toplam 600 kişinin hayatını kaybettiği zelzelede $1462 \mathrm{ev}$, 867 dükkân tamamen yıkıldı. 1200'den fazla ev oturulamayacak hâle geldi. Şehirde deprem sonrası 320 ile 330 kişi hayatını kaybetmiştir. Ölenlerin 72'si erkek, 80'i kadındı. Ayrıca 171 kadar da çocuk can vermişti. Yirmi altı cami ve mescitle altmış medrese ve mektep, altmış iki han ve hamam ya tamamen ya da kısmen tahrip oldu (BA, İradeMeclis-i Mahsûs, nr. 629, 650). Şehri bu hâle sokan deprem 15 saniye sürmüştü (Ceridei Havadis, nr.941, 19 ZA. 1275).

$\mathrm{Bu}$ büyük ve yıkıcı depremin haberi dönemin Erzurum Valisi Arif Paşa tarafından Bâbıali'ye ancak bir gün sonra bildirilmişti. Vali Paşa, halkın durumu ve depremin yaptığı tahribat hakkında henüz kesin bir sonuca varılmadığını, bunun için belirli bir zamana ihtiyaç olduğunu belirtti. Depremin şiddetli olduğu ikinci gün Anadolu ordusuna mensup askerlerden 7'si vefat ederken 9'u da yaralanmıştı. Arif Paşa, şehrin ve ahalinin durumunu şöyle açıklar: "Depremin artçı sarsıntıları cuma günü bile devam etmektedir. Erzurum şehrinin merkezi 7000 haneden fazla olup bunun yarısı tamamen yıkılmıştır. Diğer evlerle dükkân, cami ve minarelerin bazısının yarısı bazısının da üçte biri yerle bir olmuştur. Şehirdeki binaların çoğu tahrip olmuş tamire muhtaç hâle gelmişti. Henüz sarsıntıların arkası kesilmediğinden bütün halk ve memurlar şehir dışına çıkmış olup kimse şehre girmeye cesaret edememekteydi. Halk, çoluk çocuk ve aileleriyle birlikte şehir dışında gecelemekteydiler. Mevsimin yaz olması olası bir faciayı engellemekteydi. Erzurum halkının çoğu fakir ve yiyecek ekmeğe muhtaç olduğundan evlerini yeniden inşa etmeye asla kudretleri yoktu. Zaten Erzurum şehri ve halkı Kırım Harbi'nden dolayı önemli bir yıkım yaşamıştı. Zelzelenin verdiği bu son darbe burasını büsbütün sefalete sürüklemişti. En ciddi sıkıntı ise barınma sorunuydu. Çünkü yeterli sayıda halka yetecek çadır mevcut değildi” (Tozlu 2002: 101).

Erzurum havalisinde yaşanan 1/2 Haziran 1859 tarihli deprem şehre büyük zararlar vermişti. Bu tahribattan şehirde bulunan cami, medrese, han, hamam gibi sosyal tesisler de nasiplerini almışlardı. Bu elim durum karşısında Vali Arif Paşa, Bâbıali’ye detaylı 
izahat vererek yardım talebinde bulunmuştu. Vali Paşa'nın bu isteğine Bâbıali şu cevabı vermişti:

Evkâf-1 Hümâyûn Nazırı Devletlü Paşa Hazretlerinin 17 Muharrem 1276 tarihiyle Meclis-i Vâlâ'ya havale buyurulan bir kıt'a tezkiresiyle melfuf hülasa defteri meallerinde Erzurum'da vuku' bulan hareket-i arzdan dolayı harap olarak muhtaç-1 ta'mir bulunan cevami' ve mesacid ile han ve hamam vesairenin bervechi tahmin mesarif-i mukteziyesi 7 yük 99000 kuruşa baliğ olup 4 yük bu kadar kuruş Maliye ve Evkaf-1 Hümâyûn-u hazineleriyle vakıflarının mevdud fazlalarından ruyet olunacak ise de küsurunun tesriyesine mahalli evkaf hasılatının tahammülü olmadığ 1 gibi hazine-i evkafın dahi müsaadesi olmadığından iktizası isti'zan olunmuş olup bunlar âsâr ve müberrat-1 celileden olmasıyla böyle hal-i harapta bırakılması caiz olmayacağından saye-i meal-i vaye-i hazret-i şâhânede icrâ-yı tamiratı ehem ve elzem olduğuna ve mesârif-i tamiriyesi 4 yük bu kadar bin kuruşa keşf ve tahmin kılınan mahallerden ekserisinin tesriye masraflarına vakıflar müsaid olduğu gibi maliye hazine-i celilesinden rüyeti gösterilen masraf mezkûr defterde gösterildiği vechile cennetmekân Sultan Süleyman Hazretleri'nin ihyâ-kerdeleri olan camii şerifin tahmin olunan 100 bin kuruş masarıf-1 tamiriyesi olup camii mezkurun vâridât ve masarifâtı hazine-i celile-i maliyeden ru'yet olunmakta olmasıyla bu akçenin dahi oradan tesriyesi tabiat-1 maslahattan olacağına binaen masarıfına karşılık olmayan mahallerin bundan böyle vakıflarından fazla zuhur ettikçe veya âhâr karşılık bulundukça tamirât-1 mukteziyesine bakılmak üzere 4 yük bu kadar bin kuruş masraf tahmin kılınan mahallerin şimdiden icrâ-yı tamirat zımmında hazinece icrâ-yı icabının nazır-1 müşârûnileyh hazretlerine havalesiyle maliye nezâret-i celilesine dahi beyân-1 keyfiyet olunması Meclis-i Vâlâ'da tezekkür kılınmış ise de ol babda emr û ferman hazret-i memleün emrindir (BOA. İ.MVL. 422/18488-17 Safer 1276/12 Eylül 1859).

Yukarıda tam metni verilen belgeden, Erzurum'da 1859 yilında vuku bulan depremin şehre büyük zararlar verdiği şehrin cami, medrese, mescit gibi yapılarının kullanılmayacak bir durumda olduğu anlaşılmaktadır. Bu büyük tahribatların tamir edilmesi için çok ciddi paralara ihtiyaç olduğu ancak devlet hazinesinin buna müsait olmadığı görülmektedir. Her şeye rağmen Osmanlı maliyesi bu yaraların ne pahasına olursa olsun sarılacağı müjdesini bildirmiştir. Depremin bu tahribatlarının bir kısmı devlet hazinesinden bir kısmı da vakıfların gelirlerinden ayrılan paydan karşılanacaktı.

Babıâli deprem haberini alınca durum değerlendirmesi yaparak acilen nakdî yardım yapılmasına karar verdi. Dönemin padişahı Sultan Abdülmecid'in emriyle Erzurum'a ivedi olarak 3000 kese akçe gönderildi. Ayrıca Erzurum'da bu afetin durumunu incelemek ve gerekli çalışmaları yürütmek maksadıyla Münip Paşa geniş yetkilerle görevlendirildi (BOA, İrade-i meclis-i Mahsus, nr. 629).

Erzurum'a yardım noktasında sadece devlet yardımı yeterli olmayacaktı. Elbette çevre illerden gelen yardımlar da yaraların sarılmasına, acıların dindirilmesine katkı 
sağlayacaktı. Bu durumda Erzurum'a yardım edecek en yakın komşu Trabzon ${ }^{1}$ vilayetiydi. Dolayısıyla ilk olarak Trabzon Valiliği haberdar edildi. Hatta Erzurum Valisi Arif Paşa, şehrin perişanlığını tarif etmek ve derhal yardım almak için yalnızca Trabzon Valiliğine yazı yazmıştı. Trabzon ve bağlı idari birimlerden toplanacak paranın asgari sınırı kişi başına 20 kuruştu ve bu da yaklaşık olarak 143. 945 kuruş gibi bir miktara ulaşıyordu. Bu meblağın 23.728 kuruşu Erzurum'a acilen gönderilmişti. Söz konusu nakdî yardım Trabzon ve Trabzon'a bağlı Görele, Vakfısagir, Of, Sürmene, Akçaabad, Tonya dâhil Vakfikebir, Rize Keşab, Tirebolu ve Ordu sancağından toplanmıştı. Ayrıca Gümüşhane sancağı da 20.900 kuruş yardımı Trabzon'a göndermişti. Toplanan bu yardım yaklaşık 100.000 kuruş gibi önemli bir meblağa ulaşmıştı. Trabzon vilayetince toplanan 100.000 kuruşun ancak 60.000 kuruşu Erzurum'a gönderilebilmişti. Paranın geri kalan kısmı o tarihlerde oldukça yardıma muhtaç olan ve Trabzon'a gelmeye çalışan Nogay göçmenlerine dağıtılmıştı (Tozlu 2002: 104-105).

Yaşanan her büyük zelzeleden sonra artçı sarsıntıların yaşanması kaçınılmaz bir gerçekti. 2 Haziran 1859 depreminin ardından şehirde aralıklarla artçı sarsıntılar meydana geldi (Ceride-i Havadis nr. 944, 8 Zilhicce 1275/9Temmuz 1859). Ancak ilk zelzeleden yaklaşık bir ay sonra şehirde artçı sarsıntılar kendini göstermeye başladı. Bu artçı sarsıntıların en etkili olanı 15 Temmuz 1859 tarihinde meydana geldi. Bu sarsintı sırasında şehirde bazı ev, dükkân ve yapılar zarar görmüş olup herhangi bir ölüm olayı olmadığı anlaşılmıştır (Ceride-i Havadis nr. 948, 9 Muharrem 1276/8 Ağustos 1859).

Erzurum'da yaşanan 1859 depreminden sonra ilerleyen tarihlerde bazı depremler olduğu görülmektedir. Dikkate değer zelzelelerden biri 12 Haziran 1866 tarihinde Erzurum, Muş ve Varto gibi yerleşim yerlerinde meydana gelmiştir. Muş ve Varto dışında kalan bu yerlerde herhangi bir can kaybı yaşanmamıştır. Muş ve Varto'nun bazı köylerinde bu depremde yaklaşık 200 vatandaş hayatını kaybetmiştir (A. Lütfî Efendi 1989: 42). Ayrıca bu depremden iki yıl sonra 1868 yılında da Erzurum'da deprem meydana gelmiş ancak mal ve can kaybı yaşanmamıştır (A. Lütfî Efendi 1989: 15) . 20. yüzyıl başlarında 1909 ve 1910 yıllarında Erzurum'da çeşitli depremlerin yaşandığı ancak küçük çaplı depremler olduğu dönemin önemli gazetesi olan Tanin'de haber olarak yer almıştır. Cumhuriyet'in ilk yıllarında (1924) Erzurum'da etkili depremler yaşandığı bilinmektedir. Bundan başka Erzurum ve çevresinde 20 Ağustos 1946, 17 Ağustos 1949, 3 Ocak 1952, 7 Mart 1966,

\footnotetext{
${ }^{1}$ Trabzon vilayetinden Erzurum'a yapılacak yardım hakkında detaylı bilgi için bkz. BOA. A.MKT.UM. nr. 337/87; BOA. A.MKT.UM. 355/43; I.DH. nr. 28841.
} 
30 Ekim 1983 tarihlerinde yıkıcı depremler yaşanmış can ve mal kaybı meydana gelmiştir.

\section{SONUÇ}

Depremler, hiç şüphesiz ki şehirlere verdiği zarar, tahribat ve halka olan tesirleri ile doğal afetler arasında en korkunçlarından biri kabul edilir. Erzurum şehrinin deprem fay hattı üzerinde olması bu gerçeği her zaman hatırlatmıştır. Şehir su potansiyeli bakımından oldukça zengin sayllabilecek bir konumdadır. Erzurum'un hemen hemen eski mahallelerinin çoğunda yer sularının aktığı çeşmeler şehre ayrı bir hava katar. Ancak depremin su yollarının tahrip olmasına sebebiyet vermesi, tehlikeyi de beraberinde getirmiştir. O yıllarda açıktan akmakta olan kanallara karışan bu sular halkın sağlığını önemli ölçüde tehdit etmiş, hatta salgın hastalıklara yol açmıştır.

Erzurum'u harabe hâline sokan 1859 depremi geride hafizalardan silinmeyecek derin tesirler bırakmıştır. Şehirdeki evlerin büyük bir kısmı ya yıkılmış ya da oturulmayacak duruma gelmiştir. Bütün bu olumsuz duruma rağmen devletin desteği ile tahrip olan evlerin büyük bir kısmı kışa kavuşturularak vatandaşın soğuktan korunup oturabileceği bir düzene getirilmeye çalışılmıştır.

Sonuç olarak, resmî makamlar mevcut şartların elverişsizliğine; o günkü ulaşım, haberleşme yetersizliği ve teknik yetersizliğe rağmen imkânlar nispetinde hareket etmişler ve gelen seri raporları değerlendirerek gerekli talimatı hazırlayıp mahalline ulaştırmışlardır.

\section{KAYNAKÇA}

\section{Arşiv Vesikaları}

BOA. A.MKT.UM. $n r .337 / 87$, nr. $355 / 43$

BOA. I.DH. nr. 28841.

BOA, Irade-Meclis-i Mahsûs, nr. 629, 650

BOA. Irade Meclisi-i Vala, nr. 422/18488

\section{Kitap ve Araştırma Eserleri}

AMBRASEYS N. N. - FINKEL C. F (1995). Seismicity of Turkey and Adjacent Areas, a Historical Review: 1500-1800, İstanbul.

ARSLANTAŞ, Nuh (2013). "Zelzele”, IA, C.44, İstanbul. 
ATABEY, Eşref (2000). Deprem, Ankara.

Ahmet Cevdet Paşa (1986). Tezâkir (13-20), haz. Cavid Baysun, İstanbul.

Ahmet Lûtfî Efendi (1986). Vak'anüvis Ahmet Lûtfí Efendi Târihi, IX, haz. M. Münir Aktepe, İstanbul.

Bayındırlık ve İskân Bakanlığı (1986). Teknik ve Uygulama Genel Müdürlüğü,

Deprem, Ankara.

CUINET, Vital (1892). La Turquie D’Asie, I, Paris.

CURZON, Robert (1854). Armenia: A Year at Erzeroom and the Frontters of Russia, Turkey and Persia, London.

DEVELLIOĞLUU, Ferit (1995). Osmanlıca-Türkçe Lûgat, haz. Aydın Sami Güneyçal, Ankara.

GÜNER, İbrahim vd. (2007). Genel Coğrafya, Ankara: Pegem Yayıncılık.

KONUKÇU, Enver (1992). Selçuklulardan Cumhuriyete Erzurum, Ankara.

KÜÇÜK, Cevdet (1975). Tanzimat Devrinde Erzurum, İstanbul Üniversitesi Edebiyat Fakültesi Basılmamış Doktora Tezi, İstanbul.

Muallim Naci (2009). Lugat-i Naci, Ankara: TDK Yayınları.

SAKİN, Orhan (2002). Tarihsel Kaynaklarlyla İstanbul Depremleri, İstanbul.

Şemseddin Sami (1317). Kâmûs-i Türkî, Dersaadet.

ÖZGÜR, H. (1952). Deprem Bilgisi (Sismoloji), Ankara.

TOZLU, Selahattin (2002). "Erzurum Tarihinde Depremler", Tarih Boyunca

Anadolu'da Doğal Âfetler ve Deprem Semineri, Bildiriler (22-23 Mayıs 2000), 2.

Bask1, İstanbul.

\section{Gazete}

Ceride-i Havadis, nr.941, 944, 948. 